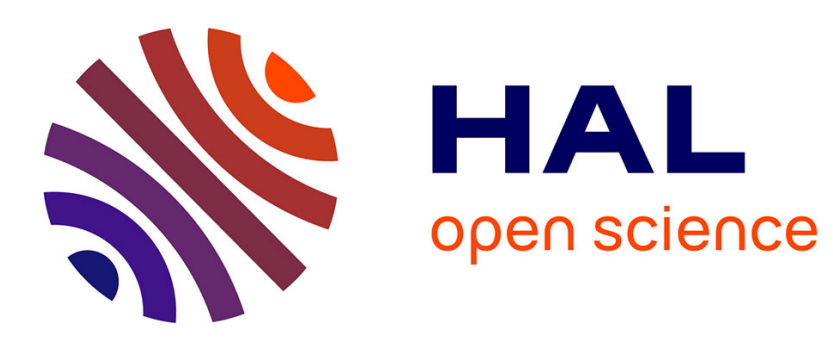

\title{
Towards Semantic Digital Games for Semantic Digital Libraries
}

\author{
Owen Sacco, Georgios N. Yannakakis
}

\section{To cite this version:}

Owen Sacco, Georgios N. Yannakakis. Towards Semantic Digital Games for Semantic Digital Libraries. ELPUB 2020 24rd edition of the International Conference on Electronic Publishing, Apr 2020, Doha, Qatar. 10.4000/proceedings.elpub.2020.3 . hal-02544927

\section{HAL Id: hal-02544927 https://hal.science/hal-02544927}

Submitted on 16 Apr 2020

HAL is a multi-disciplinary open access archive for the deposit and dissemination of scientific research documents, whether they are published or not. The documents may come from teaching and research institutions in France or abroad, or from public or private research centers.
L'archive ouverte pluridisciplinaire HAL, est destinée au dépôt et à la diffusion de documents scientifiques de niveau recherche, publiés ou non, émanant des établissements d'enseignement et de recherche français ou étrangers, des laboratoires publics ou privés. 


\title{
Towards Semantic Digital Games for Semantic Digital Libraries
}

\author{
Owen Sacco and Georgios N. Yannakakis
}

\section{Introduction}

1 The Web has revolutionised access to knowledge, making information and knowledge more easily accessible. This involved digitising information, organising digital information in collections, and providing access through complex Web information systems known as digital libraries. Digital Libraries have changed the idealisation of traditional libraries as being the central institutions for knowledge acquisition (D. M. Levy and C. C. Marshall, 95). Several types of digital libraries exist such as digital libraries for cultural heritage, health, government, learning, science and digital games (Fuhr et al., 2007). Digital libraries offer technological- enabled services that support both information producers and information consumers (Soergel 2009). Functionality and services include information search and retrieval, information storage including storing multimedia, cataloguing, user interfaces and telecommunications.

2 The Web of Data is evolving the Web to be consumed both by machines and humans, whereas the traditional Web resulted in being for human consumption only. Indeed, machines cannot process additional meaning from the content found in Web pages since they are simply text and similarly from the non-typed links which do not contain any additional meaning about the relationships amongst the linked pages. Therefore, the Web of Data provides various open data formats which have emerged from the Semantic Web.

3 The Semantic Web (Tim Berners-Lee et al., 2001) provides approaches for structuring information on the Web by using metadata to describe Web data. The advantage of using metadata is that information is added with meaning whereby Web agents or Webenabled devices can process such meaning to carry out complex tasks automatically on behalf of users. Another advantage is that the semantics in metadata improved the way information is presented, for instance merging information from heterogeneous 
sources based on the relationships amongst data, even if the underlying data schemata differ. Therefore, the Semantic Web encouraged the creation of meta-formats to describe metadata that can be processed by machines to infer additional information, to allow for data sharing and to allow for interoperability amongst Web pages. The common format and recommended by W3C for Semantic data representation (Tim Berners-Lee 1998 ) is the Resource Description Framework (RDF) ${ }^{1}$.

The Semantic Web evolved digital libraries into Semantic Digital Libraries that provide more efficient solutions for accessing content and metadata. Semantic Digital Libraries offer additional benefits over digital libraries including integrating information from different metadata sources, provide interoperability with other Web systems, and deliver more robust, personal, user-friendly and adaptable search and browsing interfaces empowered by semantics, community interactions, user profiles, and reasoning and recommendation systems (Kruk \& McDaniel 2007).

\section{Digital Games and the Semantic Web}

Digital Games, apart from being popular entertainment whereby players immerse themselves and interact with an interactive program, have also gained popularity as educational tools. Digital Games are composed of different domains (or facets) that contribute to the game's look, feel and experience (Liapis et al. 2017). These facets include visuals, audio, narrative, gameplay, game design and level design. Each facet can be regarded as an independent model containing specific content, and a game is created when each of these models are interlinked together based on the game's requirements.

Digital Games have also been used in library institutions that include: trivia games players answer online trivia questions, and correct answers allow them to progress towards a reward; role-playing games - allow players to take on an identity and interact with virtual worlds; casual games - small games that have clear goals, are easy to learn and are based on basic concepts such as sorting or finding; games that mix physical and virtual - players interact with real-world materials and with other people through online activities; alternate reality games - online story-driven games which take place in real-time whereby the story is affected by the players' actions; and social games - games that use networking technology to allow players to collaborate or compete on large scales (Broussard 2012). Most of these games for library institutions focus mainly on information literacy through game-based learning and gamification. Some University libraries also adopted gamification to incentivise library usage amongst students - for instance they have used the service Lemontree ${ }^{2}$ that links students' library accounts to award points for specific library activities such as checking out a book (Pho \& Dinscore, 2015).

7 Apart from digital games, Virtual Reality (VR) and Augmented Reality (AR) are being introduced to libraries to simulate an immersive sensory experience by means of headsets and smart devices (Massis 2015). VR technology offers new immersive virtual experiences and interactions that can simulate real-world environments without having to be physically present in such environments or even simulate completely different real-world environments. AR technology offers additional content as overlay layers of media onto real-world objects (without replacing the real-world objects). For example, SelvAR ${ }^{3}$ can scan any library material and overlay a red $\mathrm{X}$ over any item that 
is out of place on the shelf. However, VR and AR technologies are not yet widely used in libraries.

8 Inclusion of digital real-world data (e.g. recent news, real landscapes or historical events) in game environment is a practice used to increase the reality of scenarios and game play. Many flight simulators (e.g. Microsoft Flight Simulator ${ }^{4}$ ) include digital models of objects such as actual landscapes or airports and combine them with multiplayer mode to provide more realistic experiences. This trend is also visible in some of the sports games, such as the EA Sports FIFA ${ }^{5}$ series where real-world football player statistics and data, and real-world football pitches' data are used in the game. The inclusion of historical events is especially visible in strategic games where players can participate in scenarios resembling actual campaigns and immerse in history such as the Call of Duty ${ }^{6}$ series or the Medal of Honor ${ }^{7}$ series. Moreover, games often include historical information within the plot that gamers can interact with, such as in the Assassin's Creed ${ }^{8}$ series, which contributes to a more immersive gaming experience. However, most of this content is currently created manually even though such information is widely available on the Web. Moreover, real-world data is not used for creating games for digital libraries.

Current work on automatic generation of content comprises of algorithms that generate limited in-gamee entities, such as SpeedTree (IDV 2017) that generates trees and vegetation as part of the visuals facet, or the Ludi system (Browne \& Maire 2010) which generates game rules for two-player board games as part of the game design facet. Although such algorithms are beneficial for automatic generation of content, it is still rare that more than one domain is considered e.g. in the work of Cook et al. (2014), Lopes et al. (2015) and Riedl et al. (2011) requiring a substantial amount of manual effort by game developers to create content.

10 The Semantic Web has also evolved Digital Games into the concept of Semantic Digital Games whereby content is automatically generated from semantically enriched information extracted from the Web using Semantic Web technologies. In our previous work (Sacco et al. 2016) we had proposed methods on how information is extracted and semantically-enriched from Web data for automatic content generation in games. We had also developed a light-weight vocabulary for describing character models (Sacco et al. 2017) and also created a light-weight vocabulary for linking in-game events and entities to social data (Sacco et al. 2012). Moreover, similar work in Green et al. (2019) and Barros et al. (2018) demonstrate how to create mystery adventure games from open data, mainly from DBpedia ${ }^{9}$ datasets which contain semantically enriched content extracted from Wikipedia ${ }^{10}$. However, both in our previous work and the current state of the art have not examined how semantic digital games can be used for semantic digital libraries and focused on using DBpedia rather than harvesting more linked-data and open datasets.

\section{Future work}

The purpose of this extended abstract is to provide the context for topics, which would further be discussed in the paper and subsequent publications. We will be examining what type of game designs (including VR and AR applications) are suitable for digital libraries to motivate both producing and consuming library content in order to offer a personalised experience to using digital libraries. In addition, we will be exploring how 
leveraging Semantic Web technologies can help to create personalised digital games (including VR and AR applications) for using digital libraries generated from various open and linked datasets. Our further work will focus on utilising research in Semantic Web technologies for user modelling, digital libraries, data-driven video games, VR/AR experiences, and automatic content generation for digital libraries, digital games and VR/AR applications. Through this research, user profile information, digital library content and video game content from various Web sources would be gathered and transformed into semantically enriched models and linked to already existing semantic datasets, that would be interoperable amongst different games and digital libraries. With user profile information, player preferences could be inferred that would guide the automatic generation of customised and personalised experiences. In the end, this research would benefit the Semantic Web community, the Digital Libraries community, the Digital Games community and the VR/AR community that would propose research towards semantic digital games for semantic digital libraries.

\section{BIBLIOGRAPHY}

Barros, Gabriella et al., "Who killed Albert Einstein? from open data to murder mystery games.," IEEE Transactions on Games, vol. 11, no. 1, 2018, pp. 79-89.

Berners-Lee, Tim, Hendler, James \& Ola Lassila, “The Semantic Web," Scientific American, vol. 284, 2001, pp. 34-43.

Berners-Lee, Tim. “Semantic Web Road Map,” September 1998, www.w3.org/DesignIssues/ Semantic.html.

Broussard, Mary J Snyder, "Digital games in academic libraries: a review of games and suggested best practices," Reference Services Review, vol. 40, no. 1, 2012, pp. 75-89.

Browne, Cameron \& Frederic Maire, "Evolutionary Game Design," IEEE Transactions on Computational Intelligence and AI in Games, vol. 2, no. 1, 2010, pp. 1-16.

Cook,Michael et al., “Automating Game Design in Three Dimensions," AISB Symposium on AI and Games, 2014.

Fuhr, Norbert et al., "Evaluation of digital libraries," International Journal on Digital Libraries, no. 8, 2007, pp. 21-38.

Green, Michael et al., "DATA Agent," in International Conference on the Foundations of Digital Games, 2019.

Hartsook, Ken et al., "Toward supporting stories with procedurally generated game worlds," in IEEE Conference on Computational Intelligence and Games (CIG), 2011.

IDV. “Interactive Data Visualization, “SpeedTree," Interactive Data Visualization, Inc. (IDV), 2017, store.speedtree.com/.

Kruk, Sebastian \& Bill McDaniel, "Goals of Semantic Digital Libraries," in Semantic Digital Libraries, Springer, Berlin, Heidelberg, 2009, pp. 71-76. 
Levy, David M. and Catherine Marshall, "Going digital: a look at assumptions underlying digital libraries," Communications of the ACM, 1995, pp. 77-84.

Liapis, Antonios et al., "Computational Game Creativity," in Fifth International Conference on Computational Creativity. ICCC'14, 2014.

Lopes, Phile et al., "Sonancia: Sonification of procedurally generated game levels," in $1^{\text {st }}$ Computational Creativity and Games Workshop, 2015.

Massis, Bruce, "Using virtual and augmented reality in the library", New Library World, vol. 116, no. 11/12, 2015, pp. 769-799.

Pho, Annie \& Amanda Dinscore, “Game-based learning," Tips and Trends, 2015.

Sacco, Owen et al., "A holistic approach for semantic-based game generation," in IEEE Conference on Computational Intelligence and Games (CIG), 2016.

Sacco, Owen et al., "Game character ontology (GCO) a vocabulary for extracting and describing game character information from web content.," in International Conference on Semantic Systems, 2017.

Sacco, Owen et al., "Linking in-game events and entities to social data on the web.," in IEEE International Games Innovation Conference, 2012.

Soergel, Dagobert, "Digital Libraries and Knowledge Organization." in Semantic Digital Libraries, Springer, Berlin, Heidelberg, 2009, pp. 9-39.

\section{NOTES}

1. RDF - http://www.w3.org/TR/REC-rdf-syntax/.

2. Lemontree (ended in July 2017) - https://library.hud.ac.uk/pages/lemontree/.

3. ShelvAR - http://www.shelvar.com/.

4. Microsoft Flight Simulator - https://www.xbox.com/en-US/games/microsoft-flight-simulator.

5. EA SPORTS FIFA Series - https://www.ea.com/games/fifa.

6. Call of Duty Series - https://www.callofduty.com/.

7. Medal of Honor Series - https://www.ea.com/games/medal-of-honor.

8. Assassin's Creed Series - https://assassinscreed.ubisoft.com/game/en-us/games.

9. DBpedia - http://dbpedia.org/.

10. Wikipedia - https://www.wikipedia.org/.

\section{ABSTRACTS}

The purpose of this paper is to set the scene for further twofold exploratory studies: first, in examining what type of game designs are suitable for digital libraries to motivate both producing and consuming library content in order to offer a personalised experience to using digital libraries, and second, in exploring how to leverage Semantic Web technologies to create personalised digital games (including VR and AR applications) for using digital libraries generated from various open and linked datasets. We are providing an overview of the 
development of games and semantic technologies as a basis for a better understanding of the role of games in current digital resources provision.

INDEX

Keywords: semantics, digital games, digital libraries

\section{AUTHORS}

OWEN SACCO

Institute of ICT,

Malta College of Arts, Science and Technology, Malta owensacco@gmail.com

(corresponding author)

GEORGIOS N. YANNAKAKIS

Institute of Digital Games, University of Malta, Malta 